\title{
Os machos nos papéis e os papéis dos machos: masculinidades através da escrita literária no Piauí do início do século $\mathrm{XX}$
}

\author{
História e masculinidades: a \\ prática escriturística dos literatos e \\ as vivências no início do século XX.
}

CASTELO BRANCO, Pedro Vilarinho.

Teresina: EDUFPI, 2008. 168 p.
Pedro Vilarinho Castelo Branco se graduou em História no ano de 1992 pela Universidade Federal do Piauí (UFPI), deslocando-se para Pernambuco onde concluiu o mestrado em 1995 e o doutorado em 2005, ambos em História. Ali desenvolveu sua pesquisa e escrita relacionando mulheres e cidade, e avançou em estudos ligados às relações familiares e às identidades de gênero e literatura, mediante uma abordagem sociocultural e sempre privilegiando o contexto da virada do século XIX para as primeiras décadas do XX no Piauí. Hoje, como professor adjunto da UFPI e tutor do PET de História, desenvolve atividades de ensino e extensão, além de pesquisas na área de gênero, como a coordenação do projeto de pesquisa História e masculinidades, do qual o presente livro parece ser tributário.

Tal obra mostra como o estudo das relações de gênero vem se desenvolvendo no Brasil. De acordo com Raquel Soihet e Joana Maria Pedro, em artigo publicado na Revista Brasileira de
História, o momento atual é aquele de busca de legitimidade acadêmica para o campo, e não mais o de reparar as múltiplas exclusões expressas e denunciadas pela "história das mulheres".'

No bojo desse movimento historiográfico, o trabalho de Pedro Vilarinho vem contribuir para alargar e diversificar as abordagens, ao enfatizar a importância dos estudos sobre masculinidades. Soma-se, portanto, a trabalhos como o de Durval Muniz de Albuquerque Júnior, anteriormente apontado pelas historiadoras acima como voz isolada na região nordestina, e possibilita dar novas tonalidades aos estudos de gênero e de subjetividades, além de apontar, na contemporaneidade, para uma circularidade de ideias e interesses acerca dessa temática no Nordeste brasileiro, onde profissionais de outras áreas se debruçam sobre as problemáticas de gênero.

Isso fica patente, por exemplo, no prefácio da obra elaborado pela professora Teresinha de Jesus Mesquita Queiroz. Ainda que sua carreira acadêmica seja marcada pela atenção direcionada à literatura, nesse momento ela convida o/ a leitor/a a pensar a escrita dos literatos sob uma perspectiva de gênero, ao contextualizar a produção das obras piauienses, sinalizar o embate travado entre escritores/as e analisar os diferentes discursos literários que tentariam configurar comportamentos específicos conforme o sexo. Articula e instiga a observar, portanto, temáticas presentes e imbricadas em todo o livro de Pedro Vilarinho, tais como história, literatura e gênero. 
Pedro Vilarinho escolhe como recorte temporal o momento de transição do século XIX para o XX, ou seja, o intenso período de modificações e transformações da sociedade brasileira e, em específico, da piauiense, marcado pela aceleração do urbanismo e do avanço do capitalismo, expressos no distanciamento do mundo rural, no aparelhamento da cidade e na busca pela concretização dos ideais de civilidade e modernidade. Nesse contexto, traça como principal objetivo a análise de como os modelos comportamentais foram atingidos pelos discursos proferidos, principalmente, pelos literatos, os quais, imersos em uma cultura bacharelesca, teriam atribuído ênfase às identidades femininas e, sobretudo, às masculinas.

No desenvolvimento da pesquisa e no tratamento das fontes, a vasta produção literária é escolhida entre obras na íntegra, romances, crônicas, contos, além de artigos, notícias e comentários em jornais e revistas que expressam vários discursos. Paralelamente, o autor busca informações nos relatos de vida, concedidos por meio de entrevistas, nos textos autobiográficos, submetidos à crítica, encarados e problematizados como fragmentos e vestígios de memória e elucidadores de práticas e vivências.

Seguindo uma forma de escrita dialética, nos três capítulos do livro ele constrói sua argumentação contrastando as práticas e as vivências de homens e mulheres com os discursos elaborados pelos literatos, dando foco especial aos conflitos inerentes às identidades masculinas e às suas formas de subjetivação.

Diante da modernização de Teresina e da adoção de novos costumes e outras sociabilidades, observa-se um conflito expresso na escrita literária pela negação do mundo rural e de seus aspectos diante do progresso do universo urbano. Nesse novo espaço, os discursos literários teriam uma função reformuladora, ao delinearem as formas de os sujeitos se comportarem no espaço citadino e prescreverem os modos de a sociedade vir a ser. Formariam uma espécie de teia discursiva com a função de controle dos indivíduos e de configuração de identidades de gênero.

Práticas e discursos representariam o jogo dialético (tese e antítese), enquanto as formas de recepção, tratamento e consumo dos discursos pelos indivíduos implicariam diferentes modos de subjetivação, isto é, as sínteses nesses jogos de gênero e, dessa forma, os objetivos maiores da análise de Pedro Vilarinho.

Para pensar essa dinâmica, o autor fundamenta seu trabalho em estudiosos de diferentes vertentes, como a de base hermenêutica e a de perspectiva pós-estruturalista, expressas, respectivamente, nos trabalhos de Michel De Certeau e Michel Foucault. Mediante as ideias e os conceitos trabalhados por esses filósofos, tais como consumo, prática escriturística e subjetivação, haveria a possibilidade de contrastar a produção e a recepção dos discursos, ideia essa que já havia sido sinalizada por De Certeau em crítica à ênfase dada por Foucault em relação à força e ao alcance das práticas discursivas. $^{2}$

Ainda no tratamento dos escritos de Michel Foucault, é válida uma observação quanto à leitura e à atenção dispensada por Castelo Branco a esse filósofo. De forma interessante e intrigante, ele encontra no autor de Vigiar e punir subsídios para pensar não apenas o sujeito como produto, mas também os processos de subjetivação, dinâmicos, contínuos e ininterruptos, afastando, assim, a passividade do sujeito.

O autor aponta para uma abordagem intrigante na medida em que podemos observar, por exemplo, as antinomias levantadas por Stuart Hall. De acordo com esse sociólogo, Michel Foucault teria passado por três grandes momentos em sua rica produção intelectual e somente na década de 1980, com as duas obras incompletas sobre história da sexualidade, teria se inclinado a pensar o que se chama de "sujeito":

Trata-se de um avanço importante, uma vez que, sem esquecer a existência da força objetivamente disciplinar, Foucault acena, pela primeira vez em sua grande obra, à existência de alguma paisagem interior do sujeito, de alguns mecanismos interiores de assentimento à regra, o que livra essa teorização do "behaviorismo" e do objetivismo que ameaçam certas partes do Vigiar e Punir. ${ }^{3}$

São os posicionamentos contrários que tornam ainda mais interessantes essas múltiplas possibilidades de apropriações do pensamento de Foucault, tão bem expressas na obra de Pedro Vilarinho e direcionadas para a análise das diferentes masculinidades piauienses.

De forma ampla, as masculinidades são percebidas escalonadas nas diversas fases da vida dos homens. Nesse sentido, a divisão do livro em capítulos, tal como as etapas e o desenvolvimento do corpo humano, é estruturada a partir da infância, juventude e fase adulta. Entretanto, longe de significar linearidade e homogeneidade, esses momentos apontam para a complexidade, na busca da definição das masculinidades dos indivíduos, expressa nos choques de perspectivas, temporalidades e anseios. 
É assim, por exemplo, que a escola surge como espaço segregado e afastado do mundo familiar e contribui significativamente para se pensar a infância como uma fase específica, com cuidados e tratamentos específicos às crianças, antes percebidas como adultos pequenos. Mudam-se, portanto, os discursos e as sensibilidades em relação à vida dos infantes e às formas de os meninos se subjetivarem como jovens, à medida que eles percebem outros elementos valorativos da masculinidade através do processo de escolarização.

A escola agiria como pêndulos intermitentes que ligariam as crianças a novas percepções de juventude e, em seguida, os jovens à vida adulta por meio da faculdade e da cidade, preparando-os para as novas atividades do espaço urbano.

Os discursos que influenciariam a inserção dos infantes no mundo escolar seriam contíguos àqueles que incentivariam os rapazes a darem continuidade aos seus estudos, a se inserirem no universo das letras e, cada vez mais, a se distanciarem do mundo rural e de seus tradicionalismos, isto é, de características masculinas desvalorizadas na cidade. Em termos discursivos, o aprendizado obtido através da cultura escrita seria de suma importância para os novos modos de condução das famílias e para a ocupação dos empregos urbanos e dos inéditos espaços de lazer e sociabilidade materializados na moderna Teresina do início do século XX, tais como o footing, o futebol e o cinema, espaços e dinâmicas que ofereciam outras formas de subjetivação masculina aos jovens.

Feitos homens, na idade adulta, os discursos incidiriam principalmente sobre os novos sentidos atribuídos à paternidade e às relações afetivas, além das preocupações em torno da formação do homem produtivo ligado à ideia de trabalho, de comportamentos ordeiros e disciplinados, que deveriam compor a cena urbana, o espaço público, de caráter eminentemente masculino nessa nova configuração moderna.

Em suma, o que marca as diferentes fases da vida dos homens (a infância, inclusive, inventada nesse meio) é a tentativa de modelação discursiva de suas experiências a partir da atividade literária, que, a todo custo, buscava se distanciar dos elementos e do tradicionalismo rural, através da transformação dos aspectos que compunham a masculinidade. Esses discursos, ainda que tentassem alterar o que era tido como ser macho, guardavam em seu bojo uma essência indiscutível: a dominação masculina sobre a feminina. Nesse processo, o que se alterava era apenas o modo como isso era exercido: de forma mais branda e menos violenta, pelo menos em termos.

Os alcances desses discursos são apresentados pelo autor como paradoxais e contraditórios, sinalizando uma realidade dinâmica e plural na Teresina da virada do século. Os aspectos traduzidos pela permanência de hábitos tradicionais e rurais na cidade, principalmente, pela presença de características masculinas consideradas anacrônicas, a todo instante, entravam em conflito com os discursos dos literatos.

O estudo de Pedro Vilarinho vem contribuir, assim, com uma análise mais detida e localizada das mudanças na sociedade piauiense, que pareciam sinalizar uma crise das identidades de gênero e, mais especificamente, de masculinidades, aspecto que, anteriormente, foi apontado por Elizabeth Badinter como uma grande crise de masculinidade no Ocidente, entre fins do XIX e início do XX, na qual a figura do cowboy nos EUA e a construção do tipo nordestino macho no Brasil seriam formas de reação. ${ }^{4}$

Ainda que os movimentos de valorização de novas masculinidades sejam apontados de forma ampla e genérica, o estudo de Castelo Branco denota a importância das análises mais localizadas, do escrutinar da atividade do historiador. E é somente a partir dessa ação que é possível marcar a peculiaridade e a diferença do Piauí em termos de gênero na região nordestina.

Se tomarmos, por exemplo, os estudos comparativamente, poderemos observar que tanto em Durval Muniz como em Pedro Vilarinho há a argumentação de que houve um processo reacionário, expresso nos discursos dos literatos, contra a feminização da sociedade. Para Albuquerque Júnior, a tonalidade dos discursos literários era a de condenar as transformações sociais e valorizar o passado patriarcal. Houve um resgate dos elementos que compunham a masculinidade rural diante da frivolidade do mundo urbano.

No Piauí, todavia, essa configuração ocorreu de forma diferenciada. A proposta dos literatos era a de afastamento do mundo rural, de aproximação com o mundo das letras e de configuração de novos homens urbanos e intelectualizados. Enquanto o Movimento Regionalista em Pernambuco, do qual Gilberto Freyre fazia parte, via na figura do homem de letras a ameaça do patriarcalismo rural e a feminização da sociedade, os literatos do Piauí enxergavam nesse mesmo homem novas formas positivas de ser masculino. Enfim, delinearam-se expectativas de masculinidades

Estudos Feministas, Florianópolis, 18(1): 263-275, janeiro-abril/2010 273 
distintas para uma mesma região, o Nordeste, que, assim apontadas, denotam a importância da continuidade de pesquisas sobre essa temática na atualidade.

\section{Notas}

' Rachel SOIHET e Joana Maria PEDRO, 2007.

${ }^{2}$ Michel DE CERTEAU, 2008.

${ }^{3}$ Stuart HALL, 2000, p. 125.

${ }^{4}$ ALBUQUERQUE JÚNIOR, 2003.

\section{Referências bibliográficas}

ALBUQUERQUE JÚNIOR, Durval Muniz de. Nordestino: uma invenção do falo. Maceió: Edições Catavento, 2003.
DE CERTEAU, Michel. A invenção do cotidiano: artes de fazer. Petrópolis: Vozes, 2008.

HALL, Stuart. "Quem precisa de identidade?". In: SILVA, Thomaz Tadeu da (Org.). Identidade e diferença: a perspectiva dos estudos culturais. Petrópolis: Vozes, 2000. P. 103-133.

SOIHET, Rachel; PEDRO, Joana Maria. "A emergência da pesquisa da história das mulheres e das relações de gênero". Revista Brasileira de História, São Paulo, v. 27, p. 281-300, 2007.

Mário Martins Viana Júnior Universidade Federal de Santa Catarina 